\title{
Design of a new cell penetrating peptide for DNA, siRNA and mRNA delivery
}

Salif Ali ${ }^{1}$, Candice Dussouillez ${ }^{1}$, Beatriz Padilla ${ }^{2}$, Benoît Frisch ${ }^{1}$, A. James Mason ${ }^{2}$, Antoine

$$
\operatorname{Kichler}^{1 *}
$$

Running Title : A new peptide for nucleic acid delivery

\footnotetext{
${ }^{1}$ 3Bio Team, CAMB 7199 CNRS - University of Strasbourg, Faculté de Pharmacie, 67401 Illkirch cedex, France;

${ }^{2}$ Institute of Pharmaceutical Science, School of Cancer \& Pharmaceutical Science, King's College London, Franklin-Wilkins Building, 150 Stamford Street, London SE1 9NH, UK.

*Correspondence to: kichler@unistra.fr
} 


\section{Abstract}

Background: Delivery systems, including peptide-based ones, that destabilize endosomes in a $\mathrm{pH}$-dependent manner are increasingly used to deliver cargoes of therapeutic interest such as nucleic acids and proteins into mammalian cells.

Methods: The negatively charged amphipathic alpha-helicoidal forming peptide named HELP is a derivative from the bee venom melittin and was shown to have a $\mathrm{pH}$-dependent activity with the highest lytic activity at $\mathrm{pH} 5.0$ while becoming inactive when the $\mathrm{pH}$ is increased. In the present work, we asked whether replacement in the HELP peptide of the glutamic acid residues by histidines - whose protonation state is sensitive to the $\mathrm{pH}$ changes that occur during endosomal acidification - can transform this fusogenic peptide into a carrier able to deliver different nucleic acids into mammalian cells.

Results: Our results show that the resulting HELP-4H peptide displays high plasmid DNA, siRNA and mRNA delivery capabilities. Importantly, in contrast to other cationic peptides its transfection activity was only marginally affected by the presence of serum. Using circular dichroism, we found that acidic $\mathrm{pH}$ did not induce significant conformational changes for HELP-4H.

Conclusions: Taken together, we were able to develop a new cationic histidine rich peptide able to efficiently deliver various nucleic acids into cells.

Keywords: cell penetrating peptide; cationic peptide; histidine residues; siRNA delivery; DNA transfection; mRNA vectorization 


\section{Introduction}

Amphipathic peptides are found in many species including bacteria ${ }^{1}$, insects, amphibians, humans and plants ${ }^{2-4}$. These peptides show bactericidal, fungicidal, virucidal and some even tumoricidal activities. Viral derived amphipathic peptidic motifs with biological activities such as $\mathrm{pH}$-dependent membrane destabilizing effects have also been identified. These latter motifs have attracted great attention in the 1990's since escape of therapeutics from endocytic vesicles into the cytosol is often a limiting step. This is in particular the case for therapeutic nucleic acids which remain trapped in vesicular compartments when delivered with non viral vectors. In this latter context, peptides of the N-terminus of rhinovirus HRV2 VP-1 protein 5 but above all peptides derived from the amino-terminal sequence of hemagglutinin of the influenza virus (GLFGAIAGFIEGGWTGMIDGWYG) have been largely used for increasing the endosomal escape of nucleic acids complexed with polymers ${ }^{6-9}$ or lipids ${ }^{10,11}$. These anionic peptides have a disordered conformation at $\mathrm{pH} 7$ but when the $\mathrm{pH}$ decreases the carboxyl groups of aspartic acid and glutamic acid become protonated and the disappearance of the anionic repulsion permits the adoption of an amphipathic $\alpha$-helical conformation ${ }^{9,12-14}$. This in turn allows to the peptides to interact with lipid bilayers to form pores or induce membrane fusion/lysis ${ }^{15}$. However, these delivery systems require a ternary complex composed of the DNA, a cationic vector for nucleic acid complexation and a negatively charged fusogenic peptide ${ }^{13}$. A strategy, that F. Szoka's lab was the first to explore, consisted of the development of multifunctional amphipathic peptides; in particular this group tried to confer membrane destabilizing capacities as well as DNA binding properties on the peptides. To achieve this, they started with the fusogenic GALA peptide of artificial sequence (WEAALAEALAEALAEHLAEALAEALEALAA) ${ }^{16}$ and replaced the negatively charged glutamic acid residues by cationic lysines. The resulting KALA peptide (WEAKLAKALAKALAKHLAKALAKALKACEA) was able to deliver plasmid DNA into cells without addition of another component ${ }^{17}$. A few years later, a similar strategy was applied when the negatively charged amino acids of the anionic fusogenic peptide JTS-1 ${ }^{18}$ were replaced by arginines in the ppTG20 peptide ${ }^{19}$. In 1998, the design of the peptide H5-WYG (GLFHAIAHFIHGGWHGLIHGWYG) was reported ${ }^{20}$; this peptide is analogous to the N-terminal segment of the HA-2 subunit of the influenza virus hemagglutinin (HA) which is involved in the fusion of the viral envelope with the endosomal membrane ${ }^{21}$ but several residues were replaced by histidines. H5-WYG permeabilizes the cell membranes with a great efficiency at $\mathrm{pH} 6.4$ when the histidines 
become protonated but it was not active at neutral $\mathrm{pH}$. This work showed for the first time that replacement in a fusogenic peptide of glutamyl residues by histidyl residues leads to a peptide that becomes positively charged when the $\mathrm{pH}$ decreases below $\mathrm{pH} 7.0$, and appears to efficiently permeabilize cell membranes. Following these publications, our team developed in the last years $\mathrm{pH}$-responsive cationic amphipathic peptides rich in histidine residues such as LAH4 (KKALLALALHHLAHLALHLALALKKA) and LAH4-L1 (KKALLAHALHLLALLALHLAHALKKA) which proved able to bind to plasmid DNA and favor its cell uptake and endosomal escape ${ }^{22-24}$. The high efficiency of these peptides was shown to strongly rely on histidine $\mathrm{pH}$ triggers that allow endosomal membrane destabilization and release of the cargo ${ }^{25-27}$.

In 1992, R. Moser designed an amphipathic $\alpha$-helicoidal forming peptide named HELP (Helical Erythrocyte Lysing Peptide) ${ }^{28}$. The sequence of this peptide derives from the bee venom melittin from Apis mellifera (GIGAVLKVLTTGLPALISWIKRKRQQ); it was obtained by replacing most of the residues of the hydrophobic face of the helix by Leucines (which is hydrophobic and it also has a high $\alpha$-helical potential) and some of the hydrophilic residues by glutamic acid. Four glutamic acids were put into the central region of the amphipathic peptide (Table 1) in order to promote helix destabilization by mutual charge repulsion at neutral $\mathrm{pH}$. Moser found that HELP-induced leakage of haemoglobin from erythrocytes was $\mathrm{pH}$-dependent; while at $\mathrm{pH} 5.0$ the lytic activity was high it became very low when the $\mathrm{pH}$ increased.

In the present work, we asked whether it is possible to transform the HELP peptide into a nanocarrier for nucleic acids by replacing the glutamic acid residues with histidines. Our results show that the HELP-4H peptide possesses robust DNA, siRNA and mRNA delivery capabilities. 


\section{Materials and Methods}

\subsection{Compounds}

The list of the HELP derived peptides, their sequences and Mw are given, respectively, in Table 1 and S1. The efficiency of the peptides was compared to commercial agents available from different suppliers: the cationic lipid DOTAP (Sigma-Aldrich, Saint Quentin Fallavier, France), the branched polymer polyethylenimine of $25 \mathrm{kDa}$ (B-PEI, Sigma-Aldrich, Saint Quentin Fallavier, France), and the cationic peptides Vpr55-82 (Eurogentec, Seraing, Belgium), LAH4 and LAH4-L1 (Proteogenix, Schiltigheim, France). The lipid dioleoyl-snglycero-3-phosphoethanolamine (DOPE) and chloroquine were purchased from SigmaAldrich (Saint Quentin Fallavier, France). The fusogenic peptide JTS-1 (GLFEALLELLESLWELLLEA) was synthesized by Proteogenix (Schiltigheim France). All the peptides were dissolved in sterile MilliQ water at $1 \mathrm{mg} / \mathrm{ml}$. B-PEI was used as a $10 \mathrm{mM}$ monomer aqueous stock solution and DOTAP was dissolved at $1.3 \mathrm{mM}$ in water. All the peptides and transfection reagents were stored at $-20^{\circ} \mathrm{C}$.

\subsection{Plasmids and siRNAs}

The plasmid pSMD2Luc $\Delta$ ITR $7.6 \mathrm{kbp}$ and the eGFP-C1 plasmid $4.7 \mathrm{kbp}$ (Clontech-Takara Bio, Saint-Germain-en-Laye, France) were aliquoted respectively at a concentration of 2 $\mathrm{mg} / \mathrm{mL}$ and $900 \mathrm{ng} / \mathrm{mL}$ in sterile MilliQ water and stored at $-20^{\circ} \mathrm{C}$. These two plasmids encode respectively for the luciferase gene pGL2 and for the eGFP gene (green fluorescent protein). Both genes are under the control of the human cytomegalovirus (CMV) immediateearly promoter. The following siRNAs were used in our experiments: the siRNA pGL3 that targets the mRNA of the Firefly luciferase gene expressed in A549-Luc cells (sense sequence: 5'-CUUACGCUGAGUACUUCGAdTdT, antisense sequence: 3'dTdTGAAUGCGACUCAUGAAGCU; from Eurogentec, Seraing, Belgium); the control siRNA obtained from Dharmacon that does not match with any human mRNA. Its sequence was not disclosed by the supplier.

\subsection{Circular dichroism}

Peptides were dissolved in $5 \mathrm{mM}$ Tris amine at a final concentration of between 30 and 50 $\mu \mathrm{M}$. The $\mathrm{pH}$ of the samples was titrated down by adding $0.3 \%$ or $1 \%(\mathrm{v} / \mathrm{v}) \mathrm{HClO}_{4}$ solution in microlitre amounts. $\mathrm{ClO}_{4}-$ has greater optical transparency than $\mathrm{HCl}$ (which has substantial absorbance below $200 \mathrm{~nm}$ ), hence substitution of $\mathrm{HCl}$ by $\mathrm{HClO}_{4}$ makes a significant 
improvement on spectral quality in the far-UV region. CD spectra were acquired on a ChirascanTM Spectrometer (Applied Photophysics, Leatherhead, UK) with samples maintained at $310 \mathrm{~K}$. Spectra were recorded from 260 to $180 \mathrm{~nm}$ using a $0.5 \mathrm{~mm}$ path length and were processed using Chirascan software where a spectrum of the peptide free solution was subtracted and Savitzky-Gorlay smoothing with a convolution width of 5 points applied.

\subsection{Cell Culture}

Several human cell lines have been used during the project: alveolar basal epithelial cells from a Human adenocarcinoma transfected to stably express (A549-Luc) or not (A549) the pGL3 luciferase gene; Human foetal lung fibroblasts transformed with SV40 (MRC5-V2); Human embryonic kidney cells (HEK293) and the Human colorectal carcinoma cell line HCT116. The cell lines were cultured at $37^{\circ} \mathrm{C}$ in a humid atmosphere $(5 \% \mathrm{CO} 2)$ in either Dulbecco's modified Eagle medium (DMEM) or RPMI 1640 (Roswell Park Memorial Institute) supplemented with $2 \mathrm{mM}$ L-glutamine, 100 units $/ \mathrm{mL}$ penicillin, $100 \mu \mathrm{g} / \mathrm{mL}$ streptomycin and 10\% foetal calf serum (FCS). A549-Luc cells were cultured in the presence of $0.8 \mathrm{mg} / \mathrm{mL}$ of Geneticin (G418, Promega, Charbonnières-les-Bains, France).

\subsection{Preparation of the complexes}

The peptide/DNA complexes were prepared by mixing equal volumes of DNA and peptide in $150 \mathrm{mM} \mathrm{NaCl}$. For example, $2.25 \mu \mathrm{g}$ of DNA in $50 \mu \mathrm{L}$ of $150 \mathrm{mM} \mathrm{NaCl}$ were mixed with increasing amounts of peptide in $50 \mu \mathrm{L}$ of $150 \mathrm{mM} \mathrm{NaCl}$. After vortex mixing for 20 seconds, the mixture was kept for $20 \mathrm{~min}$ at room temperature to allow the formation of the complexes. Culture medium was then added to obtain a final volume of $750 \mu \mathrm{L}$; next, $250 \mu \mathrm{L}$ were added to each well of the triplicate. The peptide/siRNA complexes were prepared by following the same protocol as the one with DNA, with the exception that the amounts of nucleic acid and the volumes of preparation of the complexes were smaller; for a triplicate, $500 \mathrm{ng}$ of siRNA/ $15 \mu \mathrm{L}$ of $150 \mathrm{mM} \mathrm{NaCl}$ were mixed with increasing amounts of peptide/15 $\mu \mathrm{L}$ of 150 $\mathrm{mM} \mathrm{NaCl}$. The final concentration of siRNA was always kept at $50 \mathrm{nM} /$ well.

\subsection{Size analysis by dynamic light scattering (DLS)}

Eight $\mu \mathrm{g}$ of HELP-4H and $1.5 \mu \mathrm{g}$ DNA (w:w ratio of 5.3/1) were each diluted in $25 \mu \mathrm{L}$ of 150 $\mathrm{mM} \mathrm{NaCl}$. After the solutions were mixed and left for $20 \mathrm{~min}$ at room temperature, $50 \mu \mathrm{L}$ of $\mathrm{NaCl}$ were added and particle size was measured using a Zetasizer nano ZS (Malvern). The same protocol was used for measuring the size of the complexes prepared in water. The 
sample for Zeta potential measurement was prepared by adding $900 \mu \mathrm{L}$ of water to the $100 \mu \mathrm{L}$ of complexes generated in $150 \mathrm{mM} \mathrm{NaCl}$.

\subsection{Transfection of plasmid DNA and siRNAs}

The transfection assays were done using 48 -well plates. These experiments were done in biological duplicates or triplicates (the same test was performed on 2-3 biological samples; i.e. we used 2-3 distinct wells/condition in the cell culture plates). Key experiments were done at least two times. The cells were seeded into the plates one or two days before transfection, in order to have a confluency of $60-80 \%$ for DNA transfections and $30-40 \%$ for siRNA transfections. For transfections realized in the absence of serum, a serum-free culture medium was mixed with the complexes in order to have a final volume of $250 \mu \mathrm{L}$ per well. After removing the culture medium, the complexes were deposited into the wells and the plates were placed into the incubator. After a period of 2.5 hours of incubation, the transfection medium was replaced by fresh medium containing $10 \%$ serum. Then, the cells were incubated at $37^{\circ} \mathrm{C}$ until the end of the experiment. For the experiments conducted in the presence of percentages of serum higher than $10 \%$, pure serum was directly added into each well using a micropipette in order to obtain the wished percentage. After $3 \mathrm{~h}$ of incubation at $37^{\circ} \mathrm{C}$, the medium was changed with fresh medium supplemented with $10 \%$ serum. The transfection experiments involving chloroquine at a final concentration of $100 \mu \mathrm{M}$ were performed as described above except that the drug was added after dilution of the complexes with RPMI, just prior to the addition of the transfection medium to the cells. The fusogenic peptide JTS-1 (1 $\mathrm{mg} / \mathrm{mL}$ solution) was added to preformed peptide (or polymer)/DNA complexes. After an incubation time of $10 \mathrm{~min}$, the transfection volume was adjusted to the desired volume with culture medium. For the complexes with DOPE the following procedure was used: DOPE, diluted in ethanol containing traces of chloroform ( $10 \mu \mathrm{L}$ per $\mathrm{mL}$ of ethanol) was added to the cationic vector prior addition of the DNA solution.

\section{8. mRNA Transfection}

The mRNA expressing luciferase (CleanCap ${ }^{\circledR}$ FLuc mRNA) was from Tebu-Bio (Le Perrayen-Yvelines, France). The transfection experiments were performed in 96-well plates. The HCT116 cells were seeded into the plates the day before transfection $(24,000$ cells/well) in order to have a confluency of $70 \%$. The peptide/mRNA complexes were prepared as follows: $0.6 \mu \mathrm{g}$ of mRNA in $15 \mu \mathrm{L}$ of $150 \mathrm{mM} \mathrm{NaCl}$ were mixed with increasing amounts of carrier 
diluted in $15 \mu \mathrm{L} 150 \mathrm{mM} \mathrm{NaCl}$. The mixture was then kept for 15-20 min at room temperature to allow the formation of the complexes. Then $120 \mu \mathrm{L}$ of serum-free culture medium were added to the complexes in order to have a final volume of $150 \mu \mathrm{L}$. After removing the culture medium, the complexes were added to the cells ( $75 \mu \mathrm{L}$ per well) and the plates were incubated at $37^{\circ} \mathrm{C}$. After 2.5 hours, the transfection medium was replaced by medium supplemented with $10 \%$ serum. Then, the cells were incubated at $37^{\circ} \mathrm{C}$ till the end of the experiment (around $24 \mathrm{~h}$ ). The luciferase quantification was done as described below.

\subsection{Determination of luciferase activity}

The dosage of the luciferase was done as described ${ }^{29}$. Briefly, the transfected cells were first lysed by adding $100 \mu \mathrm{L}$ of lysis buffer $\left(8 \mathrm{mM} \mathrm{MgCl}_{2}, 1 \mathrm{mM}\right.$ DTT, $1 \mathrm{mM}$ EDTA, $0.6 \%$ Triton $\mathrm{X}-100,15 \%$ glycerol, and $25 \mathrm{mM}$ Tris-phosphate buffer $\mathrm{pH}$ 7.8) per well after having removed the culture medium. After 15 minutes of incubation, the lysates were transferred into Eppendorf tubes and centrifuged for $5 \mathrm{~min}$ at $18000 \mathrm{~g}$. Then $1-5 \mu \mathrm{L}$ of the supernatant were deposited in wells of a white 96 well-plate. The dosage of the luciferase activity was realized with a luminometer after sequential addition of $50 \mu \mathrm{L}$ assay buffer and $50 \mu \mathrm{L}$ of a luciferin solution. The results are expressed in relative light units (RLU) and are normalized for the amount of proteins present in each sample and are expressed in RLU/1s/mg protein. Of note, the light units/s measured with untreated cells are considered as background and therefore these values are substracted from each sample. The amount of protein was determined by a Bradford assay (Biorad protein assay kit, Biorad, Marnes-la-Coquette, France). This measurement was made using $4 \mu \mathrm{L}$ of supernatant. To each sample was then added $200 \mu \mathrm{L}$ of Bradford reagent diluted at 1/5 in MilliQ water. The colorimetric assay was done by measuring the optical density (OD) at $595 \mathrm{~nm}$ using a spectrophotometer (SP Safas 2000). The amount of protein was determined using a calibration curve obtained using albumin as model protein.

\subsection{Cell viability assay}

Cell viability was determined using the "Cell growth determination kit MTT based" (SigmaAldrich, Saint Quentin Fallavier, France). The MTT assay was performed in quadruplicate in 48-well plates. To this end, 55,000 MRC5-V2 cells were seeded in 48-well plates in DMEM supplemented with $10 \%$ of serum. The next day, the cells were transfected. $24 \mathrm{~h}$ after transfection, the cells were incubated for $3 \mathrm{~h}$ at $37^{\circ} \mathrm{C}$ in the presence of $500 \mu \mathrm{L}$ of medium containing MTT reagent $(0.5 \mathrm{mg} / \mathrm{mL})$. The enzymatic reaction was stopped by removing the 
culture medium and by adding DMSO. The absorbance was then measured at $570 \mathrm{~nm}$ (and $690 \mathrm{~nm}$ ) and the percentage of cell viability was calculated relative to untreated cells (the control "untreated cells" gives the value of $100 \%$ viability). The MTT assay was performed in triplicates; the last well of the quadruplicate was used to determine the transfection efficiency since it is not possible to perform the MTT and luciferase assays on the same sample.

\subsection{Membrane integrity assay LDH (lactate dehydrogenase)}

Membrane permeabilization was determined with the "LDH Cytotoxicity Assay" kit, using the protocol of the manufacturer (Thermo Scientific, Illkirch-Graffenstaden, France). Lactate dehydrogenase $(\mathrm{LDH})$ is a cytosolic enzyme. This enzyme is not able to cross the plasma membrane. Measurement of the amount of LDH present in the supernatant of cells allows for the detection of membrane alterations. To test if our peptides possessed permeabilizing properties, we determined the amount of LDH released into the medium by measuring the optical density at $490 \mathrm{~nm}$ (and $680 \mathrm{~nm}$ ) of an aliquot of each sample after 2.5 hours of transfection. Of note, the LDH assay was performed using the same transfection plates that were used for the MTT assay. The supernatants of lysed cells (lysis buffer supplied with the kit) allows to obtain the $100 \%$ release of $\mathrm{LDH}$, whereas untreated cells provide the background release of LDH. The LDH assay was done in quadruplicate.

\subsection{Confocal microscopy}

30,000 A745-Luc cells were plated into a 8-well chamber Lab-Tek slide. The next day, cells were transfected using $2.83 \mu \mathrm{g}$ HELP-4H/167 ng siRNA-cyanine5/well (=17 $\mu \mathrm{g}$ peptide/ $\mu \mathrm{g}$ siRNA). After 2.5 hours of incubation in serum-free medium, transfection medium was removed and replaced with complete medium. After another $90 \mathrm{~min}$, cells were washed with PBS, fixed with 4\% paraformaldehyde and treated with DAPI (4',6-diamidino-2phenylindole) for nuclear staining. The cells were then imaged using a Leica DMI 4000 microscope and a X63 objective. 


\section{Results}

\subsection{Design of HELP derived peptides}

Using the bee venom melittin peptide as template, R. Moser designed a new amphipathic $\alpha$ helicoidal forming peptide named HELP (Table 1) ${ }^{28}$. The design of the peptide was performed in such a manner that the four glutamic acid residues inserted in the central region of the peptide promote helix destabilization by charge repulsion at $\mathrm{pH}$ 7.4. Interestingly however, while no $\mathrm{pH}$-dependent helix-random coil transition was observed Moser found that the peptide had a $\mathrm{pH}$ dependent membrane leakage activity (high lytic activity at $\mathrm{pH} 5.0$ that became low when the $\mathrm{pH}$ increased). Considering that endosomal escape of nucleic acids is most often a limiting step in the transfection process we asked whether minimal sequence modification of HELP could allow to obtain a cell penetrating peptide able to deliver nucleic acids.

Taking into account the four cationic amino acids (KRKR motif) at the C-terminus of HELP, it results that the net global charge of the peptide is near neutrality $(+1)$. As the C-terminus is already cationic, we asked whether replacing the four glutamic acids with histidines (to give HELP-4H) could transform this peptide into a carrier for different nucleic acids, in particular DNA, siRNA and mRNA. Table 1 shows that by exchanging the four glutamates for histidines the nominal charge increases at both, neutral $\mathrm{pH}(+5)$ and acidic $\mathrm{pH}(+9)$. In addition, three other derivatives were designed - all of which contained four histidines in the core of the peptide (Table 1). As compared with HELP-4H, the D1 derivative has 4 leucine residues that were replaced with alanines in order to reduce the hydrophobicity of the peptide. Also the 2 glutamine residues were removed. In the D2 derivative, 2 positively charged amino acids were present at each terminus instead of having all 4 cationic amino acids at the C-terminus. Also 3 point mutations were introduced as compared to D1: phenylalanine in place of glycine, serine in place of threonine and tryptophan in place of phenylalanine. Lastly in the D3 derivative - compared to HELP-4H - 3 leucine residues were replaced with alanines and point mutations were introduced at positions 3, 7 and 19. When analizing the average hydrophobicity as a function of $\mathrm{pH}$, we can see that the glutamic acid/histidine exchange makes HELP-4H more hydrophobic than HELP at pH 8 but more hydrophillic than HELP at pH 2 (Table 1). This effect will be concentrated at the centre of the peptide.

Also of note, all of the HELP-4H peptides (and LAH4-L1) increase their hydrophilicity as the $\mathrm{pH}$ drops (in contrast with HELP). Lastly, it is to mention that HELP-4H-D1 is more 
hydrophilic than the other HELP-4H peptides (even though the glutamines are removed), which underlines that the four leucine to alanine switches have an important effect. With this exception the HELP-4H peptides are generally more hydrophobic than LAH4-L1.

\subsection{Evaluation of the DNA transfection capacities of the peptides}

The DNA transfection activity of the four HELP derived peptides was tested on Human embryonic kidney cells (HEK293) using the reporter gene luciferase. As shown in Figure 1A, HELP-4H revealed to be the most efficient peptide among the four derivatives, followed by peptide D3 while the D1 and D2 derivatives were significantly less efficient. As the transfection efficiency can be cell-type dependent, the four peptides were also tested on Human colorectal carcinoma cells (HCT116 cell line). The results show that the transfection efficiency of the four HELP derivatives on these cells is comparable (Figure S1). Although peptide D3 displayed almost the same transfection potential than HELP-4H, we decided to focus on this latter peptide for the rest of the study because its sequence directly derives from the parent peptide HELP.

We first evaluated the capacity of the HELP-4H peptide to complex plasmid DNA. To this end, a gel mobility shift assay was done using increasing amounts of vector mixed with a constant amount of DNA. Results showed that approx. $2 \mu \mathrm{g}$ HELP-4H/ $\mu \mathrm{g}$ DNA were required for complete retardation (Figure S2). This corresponds - if we assume that the peptide has 5 positive charges at neutral $\mathrm{pH}$ (Table 1) - to a N/P ratio of 1 , meaning that at this ratio, the amount of cationic charges of the peptide equals the amount of negative charges provided by the phosphate groups of the DNA.

The efficiency of HELP-4H was next compared to that of the cell penetrating peptide Vpr5582 derived from the HIV-1 accessory protein Viral protein R described for having high DNA transfection capabilities ${ }^{30,31}$ and to that of the cationic polymer poly-L-Lysine with a degree of polymerization of 215 (pLys215). As shown in Figure S3A, HELP-4H was slightly more efficient than the Vpr derived peptide while performing 300x times better than polylysine. When the reporter gene GFP was used with HELP-4H, we found that a high percentage of HEK293 cells expressed the transgene (average 50\% with n=2; Figure $1 \mathrm{~B}$ and S3B).

We then evaluated the DNA transfection activity of HELP-4H on three other Human cell lines, namely Human adenocarcinoma cells (A549), Human foetal lung fibroblasts transformed with SV40 (MRC5-V2), and on HCT116 cells. For comparison, we included LAH4 ${ }^{22}$ or LAH4-L1 ${ }^{24}$, two histidine-rich amphipathic peptides we previously developed as vector for nucleic acids. Both peptides revealed to have DNA and siRNA delivery capacities 
that matches or even outperforms different commercially available cationic vectors ${ }^{22,32}$. The best HELP-4H conditions were determined for each cell line by testing several concentrations. Figures $1 \mathrm{C}$ and $\mathrm{S} 4$ show that the new peptide performed almost as well as LAH4/LAH4-L1 on the three cell lines, illustrating the good transfection capabilities of HELP-4H.

\subsection{Size and zeta potential of the complexes}

As it was previously shown that the size of DNA particles varies depending on the buffer used to generate the complexes, we measured by dynamic light scattering (DLS) the size of HELP-4H/DNA complexes prepared either in salt-free conditions or in $150 \mathrm{mM} \mathrm{NaCl}$. In the absence of salt (complexes prepared in water), we found that particles have a size around 100 $\mathrm{nm}$ (Figure S5). When generating the assemblies in $150 \mathrm{mM} \mathrm{NaCl}$, they were larger with a diameter above the micrometer $(1586 \mathrm{~nm})$. Thus, as observed previously for transfection agents like PEI ${ }^{33}$ and LAH4 ${ }^{25}$ the presence of salt induces aggregation. Next, the zeta potential of the complexes was measured and it was found to be positive $(+29.2 \mathrm{mV}$; Figure S5). This latter result was expected since the $5.3 / 1 \mathrm{w} / \mathrm{w}$ ratio which was used corresponds to a $+/$ ratio of +2.65 .

We wondered whether the small complexes generated in water possess the same transfection properties than the nanoparticles prepared in sodium chloride. The results show that the efficiency of both complexes is similar when using higher w:w ratios (Figure S6). Although the complexes generated in $150 \mathrm{mM} \mathrm{NaCl}$ were larger, we kept this latter condition for the following transfection experiments in order to be able to compare the results with the previous ones.

\subsection{Transfection in the presence of serum}

Many peptidic carriers, including LAH4 ${ }^{34}$ and LAH4-L1 ${ }^{34}$, display a DNA transfection efficiency that is reduced in the presence of serum. Therefore, we tested the gene delivery efficiency of HELP-4H in the presence of 10\% serum using three different cell lines (MRC5V2, HEK293 and HCT116). The results show that when optimising the peptide/DNA ratio, no - or only slight - reduction of the transfection activity is observed (Figure 2A and S7). Of note, as reported earlier for DOTAP based lipidic formulations ${ }^{35}$, a slight increase of the vector/DNA mass ratio is needed to compensate the serum effects (Figure 2A and S7A-B). In agreement with previous reports, LAH4's activity was altered when serum is present (Figure S7A-B). When the percentage of serum was increased to 25 and $50 \%$, we found that the 
transfection activity on MRC5-V2 cells remained very significant (Figure 2B). This was confirmed when transfecting HEK293 cells in the presence of $25 \%$ serum with the GFP reporter plasmid: the average GFP positive cell population was $71 \%(n=2)($ Figures S7C and 7D).

\subsection{Cytotoxicity of HELP-4H}

The cell toxicity of the peptide was quantified on MRC5-V2 cells in the presence of $10 \%$ serum by using an MTT assay. The results show that there is a light cell cytotoxicity when higher amounts of peptide are used (Figure 3A) but the values are in the same order than those found for other cationic vectors. In parallel to the MTT assay we determined during the same experiment the permeabilizing activity of the peptides by measuring the release of lactate dehydrogenase (LDH) from the cells 2.5 hours after having started the transfection. LDH is a cytoplasmic enzyme that cannot cross the plasma membrane; thus, the amount of $\mathrm{LDH}$ found in the medium is proportional to membrane permeabilization. The positive control for this experiment $(100 \%$ released LDH) is the amount of LDH found in the medium after complete lysis of non-transfected cells. As shown in Figure 3B, only low leakage of LDH from the cytoplasm into the culture medium was observed. Of note, one well of the quadruplicate was used to verify that the transfection efficiency worked well (data not shown).

\subsection{Endosomal escape}

Next, we asked whether inclusion of helper agents could increase the gene delivery capabilities of HELP-4H. First, we tested whether the weak base chloroquine, known to enhance the transfection activity of polymers like poly-lysines ${ }^{36}$ has an effect. As shown in Figure 4, chloroquine slightly improved the transfection efficiency of HELP-4H, while it increased by more than 10-fold the efficiency of a poly-L-lysine with an average degree of polymerization of 215 .

1,2-dioleoyl-sn-glycero-3-phosphoethanolamine (DOPE) is often used to increase the transfection capacities of cationic lipids. Here, we found that addition of DOPE improved the activity of the cationic amphipatic peptide and of the polylysine as well (Figure 4). Lastly, we asked if addition of the fusogenic amphipathic peptide JTS-1 - which was shown to have a pH-dependent lytic activity on erythrocytes ${ }^{18}$ - can boost the activity of HELP-4H. While this anionic peptide increased the transfection of pLys 215 by more than 20 -fold, it severely decreased the activity of HELP-4H suggesting that JTS-1 may disorganize the complexes due 
to its negative charges. Interestingly using the same conditions, LAH4 behaved in a very similar manner than HELP-4H (Figure 4).

It was previously reported that the acidification of the endosomes plays an important role in the transfection process of various vectors including LAH4 ${ }^{22}$ and polyethylenimines (PEI) ${ }^{37}$. Indeed, inhibition of the acidification of the endosomes by inhibitors of the $\mathrm{H}^{+}$ATPase pump, like bafilomycin $\mathrm{A} 1{ }^{38}$ or concanamycin $\mathrm{A}^{39}$ significantly decreases the transfection efficiency of these two carriers. As HELP-4H contains histidine residues that can be protonated upon acidification of endosomes, we investigated the impact in terms of transfection efficiency after inhibition of this process. MRC5-V2 cells were transfected in the presence of either bafilomycin A1 or concanamycin A. As positive control, we used B-PEI 25 $\mathrm{kDa}$ and as negative control we chose the monocationic lipid DOTAP because the protonation state of this lipid does not change within the $\mathrm{pH}$ range of 4 to 7 (amine is already fully protonated at neutral $\mathrm{pH}$ ). The results show that the efficacy of B-PEI is reduced 13- and 85times with bafilomycin A1 and concanamycin A, respectively whilst DOTAP is only marginally affected by these drugs (less than 2-times) (Figure S8A). Interestingly, the efficiency of HELP-4H was only reduced by around 3-times suggesting that acidification of the endosomes is not essential for HELP-4H to allow endosomal release of the nucleic acid. Similar results were obtained when using HCT116 cells: a dramatic decrease of B-PEI whilst DOTAP and HELP-4H were almost not affected by the presence of concanamycin A (Figure $\mathrm{S} 8 \mathrm{~B})$. Altogether, the results obtained in the presence of proton pump inhibitors suggest an intracellular mechanism of action of HELP-4H which does not strongly depend on the protonation of the imidazole groups of the histidines once the complexes are in endocytic vesicles.

\subsection{Circular dichroism}

Next we wondered whether a $\mathrm{pH}$-dependent helix-random coil transition occurs with the HELP-4H peptide. CD spectroscopy shows that LAH4-L1 undergoes a pH dependent transition from alpha-helix to disordered and previous work indicates that this is associated with disaggregation of the peptide (Fig. 5A/B) ${ }^{40,41}$. Indeed, the amphipathic $\alpha$-helix conformation of LAH4-L1 is only achievable in solution if the hydrophobic surface can be stablised by another hydrophobic surface i.e. from another peptide. For HELP-4H the same effect is not conserved and spectra consistent with $\alpha$-helix are observed at both high and low pH (Fig. 5C). Although a small, $\mathrm{pH}$ dependent, increase in the negative band at $208 \mathrm{~nm}$ is 
detected, possibly associated with decreased light scattering (Fig. 5C), based on the CD at 220 $\mathrm{nm}$, the $\alpha$-helix conformation is retained throughout the $\mathrm{pH}$ range tested (Fig. 5D).

Interestingly, this was also the case of the parent peptide HELP which showed no significant $\mathrm{pH}$-triggered conformational changes at different $\mathrm{pH}$ values ${ }^{28}$. The fact that HELP-4H maintains its $\alpha$-helix in a $\mathrm{pH}$ independent manner may explain why its transfection activity is only poorly affected by the presence of proton pump inhibitors.

The distribution of the hydrophilic and hydrophobic amino acids in the helix is represented in the helical-wheel projection in Figure S9.

Taken together, we were able to show that HELP-4H has robust DNA transfection capabilities in a variety of cell lines. Due to the high therapeutic potential of other nucleic acids, in particular of siRNAs and mRNA, we wondered if our peptide was also able to deliver them efficiently.

\section{8. siRNA and mRNA Delivery}

The capacity of the different peptides to introduce siRNAs into cells was evaluated by using A549 cells which have been engineered to stably express the reporter gene luciferase (A549Luc). As siRNA we used siLuc, which is able to silence the luciferase expression through RNA interference. The selectivity of the siLuc induced luciferase silencing is evaluated by comparison with a control siRNA ( $\mathrm{siCtrl}$ ) transfected with the peptide using the same procedure. This control proves the absence of unspecific gene down-regulation by the delivery system.

In the absence of serum, HELP-4H could induce a very good silencing since luciferase expression was reduced by more then $90 \%$ whilst control siRNA ( siCtrl) had no effect on the expression level of the reporter gene (Figure 6A). When serum was present, the silencing was less efficient but reached nevertheless 60\% compared to untreated cells (Figure 6B). Next, the delivery of the siRNA into A549-Luc cells was also investigated using confocal microscopy. The results indicate that HELP-4H has the capacity to deliver significant amounts of siRNAs into the cells (red fluorescence). Most of the fluorescence localize near the nucleus, probably in vesicular compartments, in particular endosomes (Figure 6C). These results are consistent with previous studies showing that only a very minor fraction of siRNAs is released from endosomes and this siRNA fraction remains undetectable by standard fluorescence microscopy methods ${ }^{42}$.

We then asked whether our peptide is able to switch off the expression of a gene in another cell line. For this, we used kidney tumor cells 786-O-Luc that stably express the pGL4.50 
luciferase ${ }^{43}$. The results shown in the Figure S10 indicate that HELP-4H allowed for a very important and specific decrease (90\%) of the luciferase levels in this cells line. It was noted that the optimum w/w ratio peptide/siRNA is the same as the one identified for A549-Luc cell line $(17 / 1)$.

Lastly, we wondered whether HELP-4H can allow expression of a protein after mRNA delivery. Using a luciferase expressing mRNA we transfected the Human colon carcinoma cells HCT116 with HELP-4H and DOTAP. The results indicate that both delivery systems allowed for a high expression level of luciferase (Figure 6D).

Taken together, our results show that HELP-4H is able to deliver efficiently different types of nucleic acids into cells. 


\section{Discussion}

Peptides have an interesting potential in medicine not only because their building blocks are biodegradable but also due to their small size as well as the facility of large-scale production and product characterization. During the past 3 decades, a new family of short peptides that efficiently cross biological membranes, known as cell penetrating peptides (CPPs) has emerged ${ }^{44,45}$. This discovery is promising for the development of approaches which aim to increase the intracellular delivery of compounds having a therapeutic potential but low membrane permeability, such as drugs, peptides, proteins and nucleic acids, ${ }^{46}$. Among the CPPs, arginine-rich peptides are often used. Unfortunately it was found that these peptides complexed or not to a cargo - are efficiently taken up by the cells but that endosomal escape is rather low ${ }^{47-49}$. As a consequence more efficient CPPs remain actively sought after. In the present work, we developped a new CPP based on the sequence of the fusogenic peptide HELP. Since the C-terminus is cationic we wondered whether simple replacement of the glutamic acids by histidine residues can transform this fusogenic peptide into a carrier able to deliver different nucleic acids into mammalian cells. Among the 4 derivatives that were designed and tested, HELP-4H was the most promising one. This latter peptide proved useful for the delivery of plasmid DNA but also siRNA and mRNA. This point is interesting because it was found that not all vectors able to deliver DNA are efficient for the delivery of other nucleic acids, in particular of siRNAs. This is for example the case for polyethylenimine (PEI) that belongs to the most efficient synthetic transfection agents for DNA ${ }^{50,51}$ but is a rather poor siRNA delivery agent ${ }^{52}$. Also of note, not only HELP-4H demonstrated good transfection capabilities but it proved also able to keep its transfection capabilities in the presence of serum. When the structure of the peptide was analyzed using circular dichroism, it was found that, like the HELP parent peptide, HELP-4H showed no significant pH-triggered conformational changes.

We also evaluated whether the addition of helper agents could enhance the transfection efficiency of HELP-4H. Among the 3 compounds (chloroquine, JTS-1 and DOPE) that were tested, DOPE proved the most efficient one (Figure 4). Notably, the helper activity of this zwitterionic lipid relies on its capacity to increase endosomal escape of the complexes through its fusogenic activity ${ }^{53,54}$. Interestingly DOPE has also proven able to enhance the nucleic acid transfection efficiency of non lipidic formulations, in particular of hydrophobized dodecalysines $^{55}$ and oligourea foldamers ${ }^{56,57}$. 
Finally, it has to be underlined that when we decided to insert histidine residues into HELP it was to confer to the peptide "proton-sponge" capacities, like those of PEIs or LAH4 peptides. Surprisingly however, the activity of HELP-4H in the presence of proton pump inhibitors such as bafilomycin A1 or concanamycin A was almost not altered, suggesting a mechanism of action that differs from that of LAH4. This property of HELP-4H is interesting and may reveal advantageous as compared to the LAH4 peptides: indeed, not all cellular entry pathways lead to acidification of the endocytic organelles. How exactly this new peptide acts to release the nucleic acids into the cytosol remains to be elucidated.

\section{ACKNOWLEDGEMENTS}

We thank Vanessa Schartner and Anaïs Brion for technical assistance. We would also thank for their financial contribution the Agence Nationale de la Recherche (project Biosupramol 17-CE18-0033-3) and the ITI Innovec (IdEx (ANR-10-IDEX-0002) and SFRI (ANR-20SFRI-0012).

\section{CONFLiCTS OF INTEREST STATEMENT}

The authors declare that they have no conflicts of interest.

\section{Author Contributions}

S.A, C.D., B.P. and A.J.M. performed experiments; A.J.M. analyzed data and contributed to the writing of the manuscript; A.J.M. and B.F. contributed to the design of the study; A.K. designed and supervised the study and wrote the manuscript.

\section{Data Availability Statement}

The data used to support the findings of this study are available from the corresponding author upon reasonable request.

\section{References}

1. Gradisteanu Pircalabioru G, Popa LI, Marutescu L, et al. Bacteriocins in the Era of Antibiotic Resistance: Rising to the Challenge. Pharmaceutics. 2021;13(2):196.

2. Bechinger B, Lohner K. Detergent-like actions of linear amphipathic cationic antimicrobial peptides. Biochim Biophys Acta. 2006;1758(9):1529-1539. 
3. Neelabh, Singh K, Rani J. Sequential and Structural Aspects of Antifungal Peptides from Animals, Bacteria and Fungi Based on Bioinformatics Tools. Probiotics Antimicrob Proteins 2016; 8(2):85-101.

4. Zasloff M. Antimicrobial peptides of multicellular organisms. Nature. 2002;415(6870):389-395.

5. Zauner W, Blaas D, Kuechler E, Wagner E. Rhinovirus-mediated endosomal release of transfection complexes. J Virol 1995; 69(2):1085-1092.

6. Kichler A, Freulon I, Boutin V, Mayer R, Monsigny M, Midoux P. Glycofection in the presence of anionic fusogenic peptides: a study of the parameters affecting the peptide-mediated enhancement of the transfection efficiency. J Gene Med 1999; 1(2):134-143. .

7. Kircheis R, Kichler A, Wallner G, et al. Coupling of cell-binding ligands to polyethylenimine for targeted gene delivery. Gene Ther 1997;4(5):409-418. .

8. Midoux P, Mendes C, Legrand A, et al. Specific gene transfer mediated by lactosylated poly-L-lysine into hepatoma cells. Nucleic Acids Res 1993; 21(4):871878.

9. Plank C, Oberhauser B, Mechtler K, Koch C, Wagner E. The influence of endosomedisruptive peptides on gene transfer using synthetic virus-like gene transfer systems. $J$ Biol Chem 1994; 269(17):12918-12924.

10. Kichler A, Mechtler K, Behr JP, Wagner E. Influence of membrane-active peptides on lipospermine/DNA complex mediated gene transfer. Bioconjug Chem 1997; 8(2):213221.

11. Simões S, Slepushkin V, Gaspar R, de Lima MC, Düzgüneş N. Gene delivery by negatively charged ternary complexes of DNA, cationic liposomes and transferrin or fusigenic peptides. Gene Ther 1998; 5(7):955-964.

12. Lear JD, DeGrado WF. Membrane binding and conformational properties of peptides representing the NH2 terminus of influenza HA-2. J Biol Chem. 1987; 262(14):65006505.

13. Wagner E. Application of membrane-active peptides for nonviral gene delivery. Advanced Drug Delivery Reviews 1999; 38(3):279-289.

14. Wagner E, Plank C, Zatloukal K, Cotten M, Birnstiel ML. Influenza virus hemagglutinin HA-2 N-terminal fusogenic peptides augment gene transfer by transferrin-polylysine-DNA complexes: toward a synthetic virus-like gene-transfer vehicle. Proc Natl Acad Sci U S A. 1992; 89(17):7934-7938. 
15. Takahashi S. Conformation of membrane fusion-active 20-residue peptides with or without lipid bilayers. Implication of alpha-helix formation for membrane fusion.Biochemistry 1990; 29(26):6257-6264. .

16. Li W, Nicol F, Szoka Jr FC. GALA: a designed synthetic pH-responsive amphipathic peptide with applications in drug and gene delivery. Adv Drug Deliv Rev. 2004; 56(7):967-985. .

17. Wyman TB, Nicol F, Zelphati O, Scaria PV, Plank C, Szoka FCJ. Design, synthesis, and characterization of a cationic peptide that binds to nucleic acids and permeabilizes bilayers. Biochemistry 1997; 36(10):3008-3017. .

18. Gottschalk S, Sparrow JT, Hauer J, et al. A novel DNA-peptide complex for efficient gene transfer and expression in mammalian cells. Gene Ther 1996; 3(5):448-457.

19. Rittner K, Benavente A, Bompard-Sorlet A, et al. New basic membrane-destabilizing peptides for plasmid-based gene delivery in vitro and in vivo. Mol Ther 2002; 5(2):104-114.

20. Midoux P, Kichler A, Boutin V, Maurizot JC, Monsigny M. Membrane permeabilization and efficient gene transfer by a peptide containing several histidines.Bioconjug Chem 1998; 9(2):260-267.

21. Murata M, Sugahara Y, Takahashi S, Ohnishi S-I. pH-Dependent Membrane Fusion Activity of a Synthetic Twenty Amino Acid Peptide with the Same Sequence as That of the Hydrophobic Segment of Influenza Virus Hemagglutinin. The Journal of Biochemistry. 1987; 102(4): 957-962.

22. Kichler A, Leborgne C, März J, Danos O, Bechinger B. Histidine-rich amphipathic peptide antibiotics promote efficient delivery of DNA into mammalian cells. Proc Natl Acad Sci U S A 2003; 100(4):1564-1568.

23. Lointier M, Aisenbrey C, Marquette A, Tan JH, Kichler A, Bechinger B. Membrane pore-formation correlates with the hydrophilic angle of histidine-rich amphipathic peptides with multiple biological activities. Biochim Biophys Acta Biomembr 2020; 1862(8):183212.

24. Mason AJ, Martinez A, Glaubitz C, Danos O, Kichler A, Bechinger B. The antibiotic and DNA-transfecting peptide LAH4 selectively associates with, and disorders, anionic lipids in mixed membranes. FASEB J 2006; 20(2):320-322.

25. Kichler A, Leborgne C, Danos O, Bechinger B. Characterization of the gene transfer process mediated by histidine-rich peptides. J Mol Med (Berl). 2007; 85(2):191-201. 
26. Prongidi-Fix L, Sugawara M, Bertani P, Raya J, Leborgne C, B. B. Self-promoted cellular uptake of peptide/DNA transfection complexes. Biochemistry. 2007;46(40):11253-11262.

27. Kichler A, Mason AJ, Bechinger B. Cationic amphipathic histidine-rich peptides for gene delivery. Biochim Biophys Acta 2006;1758(3):301-307.

28. Moser R. Design, synthesis and structure of an amphipathic peptide with $\mathrm{pH}$-inducible haemolytic activity. Protein Eng 1992;5(4):323-331.

29. Kichler A, Leborgne C, Savage PB, Danos O. Cationic steroid antibiotics demonstrate DNA delivery properties. J Control Release. 2005;107(1):174-182.

30. Coeytaux E, Coulaud D, Le Cam E, Danos O, Kichler A. The cationic amphipathic alpha-helix of HIV-1 viral protein R (Vpr) binds to nucleic acids, permeabilizes membranes, and efficiently transfects cells. J Biol Chem. 2003;278(20):18110-18116.

31. Marquette A, Leborgne C, Schartner V, Salnikov E, Bechinger B, Kichler A. Peptides derived from the C-terminal domain of HIV-1 Viral Protein R in lipid bilayers: Structure, membrane positioning and gene delivery. Biochim Biophys Acta Biomembr 2020;1862(2):183149.

32. Langlet-Bertin B, Leborgne C, Scherman D, Bechinger B, Mason AJ, Kichler A. Design and evaluation of histidine-rich amphipathic peptides for siRNA delivery. Pharm Res 2010;27(7):1426-1436.

33. Wightman L, Kircheis R, Rössler V, et al. Different behavior of branched and linear polyethylenimine for gene delivery in vitro and in vivo. J Gene Med. 2001;3(4):362372.

34. Mason AJ, Leborgne C, Moulay G, et al. Optimising histidine rich peptides for efficient DNA delivery in the presence of serum. J Control Release 2007;118(1):95104.

35. Yang JP, Huang L. Overcoming the inhibitory effect of serum on lipofection by increasing the charge ratio of cationic liposome to DNA. Gene Ther 1997;4(9):950960.

36. Erbacher P, Roche AC, Monsigny M, Midoux P. Putative role of chloroquine in gene transfer into a human hepatoma cell line by DNA/lactosylated polylysine complexes,. Exp Cell Res 1996;225(1):186-194.

37. Kichler A, Leborgne C, Coeytaux E, Danos O. Polyethylenimine-mediated gene delivery: a mechanistic study. J Gene Med. 2001;3(2):135-144. 
38. Yoshimori T, Yamamoto A, Moriyama Y, Futai M, Tashiro Y. Bafilomycin A1, a specific inhibitor of vacuolar-type $\mathrm{H}(+)$-ATPase, inhibits acidification and protein degradation in lysosomes of cultured cells. J Biol Chem 1991;266(26):17707-17712.

39. Dröse S, Bindseil KU, Bowman EJ, Siebers A, Zeeck A, Altendorf K. Inhibitory effect of modified bafilomycins and concanamycins on P- and V-type adenosinetriphosphatases. Biochemistry. 1993;32(15):3902-3906.

40. Iacobucci V, Di Giuseppe F, Bui TT, et al. Control of pH responsive peptide selfassociation during endocytosis is required for effective gene transfer. Biochim Biophys Acta 2012; 1818(5):1332-1341.

41. Marquette A, Mason AJ, Bechinger B. Aggregation and membrane permeabilizing properties of designed histidine-containing cationic linear peptide antibiotics. J Pept Sci 2008;14(4):488-495.

42. Gilleron J, Querbes W, Zeigerer A, et al. Image-based analysis of lipid nanoparticlemediated siRNA delivery, intracellular trafficking and endosomal escape. Nat Biotechnol 2013;31(7):638-646.

43. Neuberg P, Hamaidi I, Danilin S, et al. Polydiacetylenic nanofibers as new siRNA vehicles for in vitro and in vivo delivery. Nanoscale. 2018;10(4):1587-1590.

44. van den Berg A, Dowdy SF. Protein transduction domain delivery of therapeutic macromolecules. Curr Opin Biotechnol 2011;22(6):888-893.

45. Ramsey JD, Flynn NH. Cell-penetrating peptides transport therapeutics into cells. Pharmacol Ther 2015 154:78-86.

46. Sawant RR, Patel NR, Torchilin VP. Therapeutic delivery using cell-penetrating peptides. European Journal of Nanomedicine. 2013;5(3):141-158.

47. Hassane FS, Ivanova GD, Bolewska-Pedyczak E, et al. A peptide-based dendrimer that enhances the splice-redirecting activity of PNA conjugates in cells. Bioconjug Chem 2009;20(8):1523-1530.

48. El-Sayed A, Futaki S, Harashima H. Delivery of macromolecules using arginine-rich cell-penetrating peptides: ways to overcome endosomal entrapment. AAPS J 2009;11(1):13-22.

49. Erazo-Oliveras A, Muthukrishnan N, Baker R, Wang TY, Pellois JP. Improving the endosomal escape of cell-penetrating peptides and their cargos: strategies and challenges. Pharmaceuticals (Basel) 2012;5(11):1177-1209. 
50. Boussif O, Lezoualc'h F, Zanta MA, et al. A versatile vector for gene and oligonucleotide transfer into cells in culture and in vivo: polyethylenimine. Proc Natl Acad Sci U S A 1995;92(16):7297-7301.

51. Neuberg P, Kichler A. Recent developments in nucleic acid delivery with polyethylenimines. Adv Genet. 2014;88:263-288.

52. Zintchenko A, Philipp A, Dehshahri A, Wagner E. Simple modifications of branched PEI lead to highly efficient siRNA carriers with low toxicity. Bioconjug Chem. 2008;19(7):1448-1455.

53. Farhood H, Serbina N, Huang L. The role of dioleoyl phosphatidylethanolamine in cationic liposome mediated gene transfer. Biochim Biophys Acta. 1995;1235(2):289295.

54. Du Z, Munye MM, Tagalakis AD, Manunta MDI, Hart SL. The role of the helper lipid on the DNA transfection efficiency of lipopolyplex formulations. Scientific Reports 2014;4:7107.

55. Le Guen C, Dussouillez C, Kichler A, Chan-Seng D. Insertion of hydrophobic spacers on dodecalysines as potential transfection enhancers. European Polymer Journal. 2021;157:110654.

56. Douat C, Aisenbrey C, Antunes S, et al. A cell-penetrating foldamer with a bioreducible linkage for intracellular delivery of DNA. Angew Chem Int Ed Engl 2015;54(38):11133-11137.

57. Bornerie M, Brion A, Guichard G, Kichler A, Douat C. Delivery of siRNA by tailored cell-penetrating urea-based foldamers. Chem Commun (Camb) 2021;57((12):14581461. 
Table 1. Sequence of the HELP peptides and LAH4-L1. Nominal charges are given at $\mathrm{pH}$ 8 and $\mathrm{pH} 2$. Average hydrophobicity is given on the whole-residue hydrophobicity octanolinterface scale ( $\Delta$ Gwoct $-\Delta$ Gwif) based on the the free energy of transfer from water to palmitolyloleoylphosphatidylcholine and to $n$-octanol.

\begin{tabular}{|c|c|c|c|c|c|}
\hline \multirow[t]{2}{*}{ Peptide } & \multirow[t]{2}{*}{ Sequence } & \multicolumn{2}{|c|}{$\begin{array}{l}\text { Nominal } \\
\text { charge }\end{array}$} & \multicolumn{2}{|c|}{$\Delta G_{\text {woct }}-\Delta G_{\text {wif }}$} \\
\hline & & pH 8 & pH 2 & pH 8 & pH 2 \\
\hline HELP & GLGTLLTLLEFLLEELLEFLKRKRQQ- $\mathrm{CONH}_{2}$ & +1 & +5 & 0.265 & 0.035 \\
\hline HELP-4H & GLGTLLTLLHFLLHHLLHFLKRKRQQ- $\mathrm{CONH}_{2}$ & +5 & +9 & 0.008 & 0.228 \\
\hline HELP-4H-D1 & GLGTLATLAHFALHHLLHFAKRKR- $\mathrm{CONH}_{2}$ & +5 & +9 & 0.163 & 0.401 \\
\hline HELP-4H-D2 & RRGLFTLASLAHFALHHLLHWAKR- $\mathrm{CONH}_{2}$ & +3 & +7 & 0.053 & 0.291 \\
\hline HELP-4H-D3 & GLFTALSLLHFALHHLAHWLKRKRQQ- $\mathrm{CONH}_{2}$ & +5 & +9 & 0.081 & 0.301 \\
\hline LAH4-L1 & KKALLAHALHLLALLALHLAHALKKA- $\mathrm{CONH}_{2}$ & +5 & +9 & 0.105 & 0.325 \\
\hline
\end{tabular}




\section{Figure Legends}

Figure 1. Evaluation of the DNA transfection activity of the HELP-derived peptides on HEK293 and MRC5-V2 cells. Transfection of the Human cells was performed in duplicates (HEK293 in A) or triplicates (MRC5-V2 in C) in 48 well-plates using $0.75 \mu \mathrm{g} /$ well of a plasmid encoding for luciferase. The indicated amounts of peptide in $\mu \mathrm{g}$ are given for $1 \mu \mathrm{g}$ of DNA. The complexes were incubated with cells for 2.5 hours in serum-free medium. Thereafter, the medium was removed and replaced with serum-containing DMEM. Luciferase activity was measured approx. $28 \mathrm{~h}$ post-transfection and it is expressed as total light units/1 $\mathrm{s} / \mathrm{mg}$ protein, and the average of the duplicates is shown. Error bars represent the standard deviation of the mean. (B) Transfection of the reporter gene GFP in HEK293 cells using 48 well-plates with $5.25 \mu \mathrm{g}$ HELP-4H/1 $\mu \mathrm{g}$ eGFP-C1/well. GFP expression was analyzed $48 \mathrm{~h}$ post-transfection by using fluorescence microscopy.

Figure 2. Evaluation of the transfection activity on MRC5-V2 in the presence of serum. Transfection was performed in 48 well-plates using $0.75 \mu \mathrm{g} / \mathrm{well}$ of the plasmid encoding for luciferase. Increasing amounts of peptide were mixed in $150 \mathrm{mM} \mathrm{NaCl}$ with a constant amount of plasmid. The indicated amounts of peptide in $\mu \mathrm{g}$ are given for $1 \mu \mathrm{g}$ of DNA. The complexes were incubated with cells for 2.5 hours in medium containing or not serum. Thereafter, the medium was removed and replaced with 10\% serum-containing DMEM. Luciferase activity was measured $42 \mathrm{~h}(\mathbf{A})$ and $28 \mathrm{~h}$ (B) post-transfection and it is expressed as total light units/1 s/mg protein, and the average of the duplicates $(\mathbf{A})$ or triplicates $(\mathbf{B})$ is shown. Error bars represent the standard deviation of the mean.

\section{Figure 3. Measurement of the membranolytic and cytotoxic effects of HELP-4H.}

Increasing amounts of HELP-4H agent were mixed with a constant amount of reporter plasmid ( $3 \mu \mathrm{g}$ per quadruplicate of DNA) and the complexes were incubated for 2.5 hours with MRC5-V2 cells in 48-well plates. Using the same plates, 3 different measurements were made: (A) cell viability MTT assay ( $n=3) 24$ h post-transfection; $(\mathbf{B})$ LDH assay $(n=4)$ after the $2 \mathrm{~h} 30$ period of incubation with the complexes; and lastly luciferase activity $(\mathrm{n}=1) 24 \mathrm{~h}$ post-transfection (not shown). 
Figure 4. Transfection in the presence of helper agents. Transfection of HCT116 cells was performed in duplicates in 48 well-plates using $0.75 \mu \mathrm{g}$ DNA/well. HELP-4H was used at $2.66 \mu \mathrm{g} / \mu \mathrm{g}$ DNA, LAH4 at a w/w ratio of $8 / 1$ and pLys 215 at w/w=1.66. The complexes were incubated for 2.5 hours in serum-free medium. Thereafter, the medium was removed and replaced with serum-containing medium. Luciferase activity was measured one $24 \mathrm{~h}$ posttransfection and it is expressed as total light units $/ 1 \mathrm{~s} / \mathrm{mg}$ protein, and the average of the duplicates is shown. Error bars represent the standard deviation of the mean. Chloroquine was used at a final concentration of $100 \mu \mathrm{M}$. For generating the ternary complexes, we added respectively $5 \mu \mathrm{g}$ DOPE and $10 \mu \mathrm{g}$ JTS-1 (for a duplicate) to the HELP-4H, pLys215 and LAH4 complexes.

\section{Figure 5. HELP-4H does not undergo a substantial pH-dependent conformational} change. Far-UV CD spectra (A/C) and plots of CD @ 220 nm (B/D) show that LAH4-L1 (A/B), unlike HELP-4H (C/D), undergoes a conformational change from $\alpha$-helix to disordered conformation during acidification with a midpoint of $\mathrm{pH} 5.2$.

Figure 6. siRNA and mRNA delivery. siRNA transfection of A549-Luc cells was performed in triplicates in 48 well-plates using $0.167 \mu \mathrm{g}$ siRNA/well (= $50 \mathrm{nM})$. We used two siRNAs: one that targets the luciferase mRNA (siLuc; blue bars) and the second which is a control siRNA (siCtrl; purple bars). The indicated amounts of peptide are given for $1 \mu \mathrm{g}$ of siRNA. The complexes were incubated for $3 \mathrm{~h}$ in serum-free (A) or serum-containing (B) DMEM. Thereafter, the medium was removed and replaced with serum-containing medium. Luciferase activity was measured $48 \mathrm{~h}$ post-transfection and was expressed as total light units/1 s/mg protein. The siRNA delivery efficiency was then expressed as percent of luciferase remaining after treatment as compared to non-treated cells ( $=100 \%$; red bar). Error bars represent the standard deviation of the mean. (C) Confocal microscopy of A549-Luc cells transfected for $4 \mathrm{~h}$ with HELP-4H/siRNA-Cy5 complexes $(17 \mu \mathrm{g}$ peptide/ $\mu \mathrm{g}$ siRNA; final siRNA concentration $=50 \mathrm{nM}$ ). DAPI (blue stain) was used for nuclear staining. Images were taken using a Leica DMI 4000 microscope with a $\times 63$ objective. (D) mRNA transfection into HCT116 cells. Transfection was performed in duplicates in 96 well-plates using $0.3 \mu \mathrm{g}$ mRNA Luciferase/well. The complexes were incubated for 2.5 hours in serumfree RPMI medium. Thereafter, the medium was removed and replaced with serumcontaining medium. Luciferase activity was measured $24 \mathrm{~h}$ post-transfection. Only the best 
condition is shown for DOTAP $(\mathrm{N} / \mathrm{P}=3)$. The indicated amounts of HELP-4H peptide are given for $1 \mu \mathrm{g}$ of mRNA.
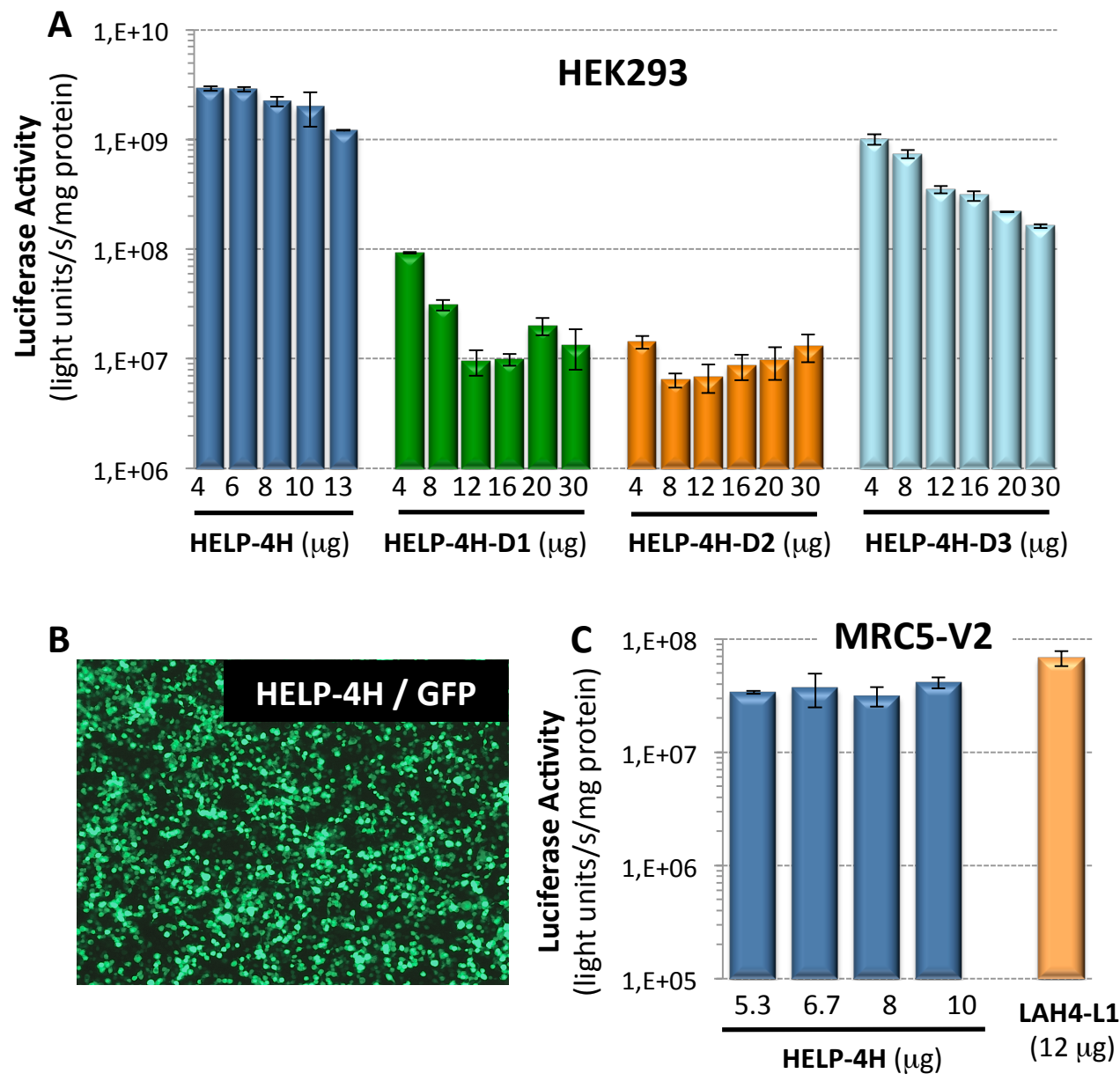

Figure 1. Evaluation of the DNA transfection activity of the HELP-derived peptides on HEK293 and MRC5-V2 cells. Transfection of the Human cells was performed in duplicates (HEK293 in A) or triplicates (MRC5-V2 in C) in 48 well-plates using $0.75 \mu \mathrm{g} / \mathrm{well}$ of a plasmid encoding for luciferase. The indicated amounts of peptide in $\mu \mathrm{g}$ are given for $1 \mu \mathrm{g}$ of DNA. The complexes were incubated with cells for 2.5 hours in serum-free medium. Thereafter, the medium was removed and replaced with serum-containing DMEM. Luciferase activity was measured approx. $28 \mathrm{~h}$ post-transfection and it is expressed as total light units/1 $\mathrm{s} / \mathrm{mg}$ protein, and the average of the duplicates is shown. Error bars represent the standard deviation of the mean. (B) Transfection of the reporter gene GFP in HEK293 cells using 48 well-plates with $5.25 \mu \mathrm{g}$ HELP-4H/1 $\mu \mathrm{g}$ eGFP-C1/well. GFP expression was analyzed $48 \mathrm{~h}$ post-transfection by using fluorescence microscopy. 

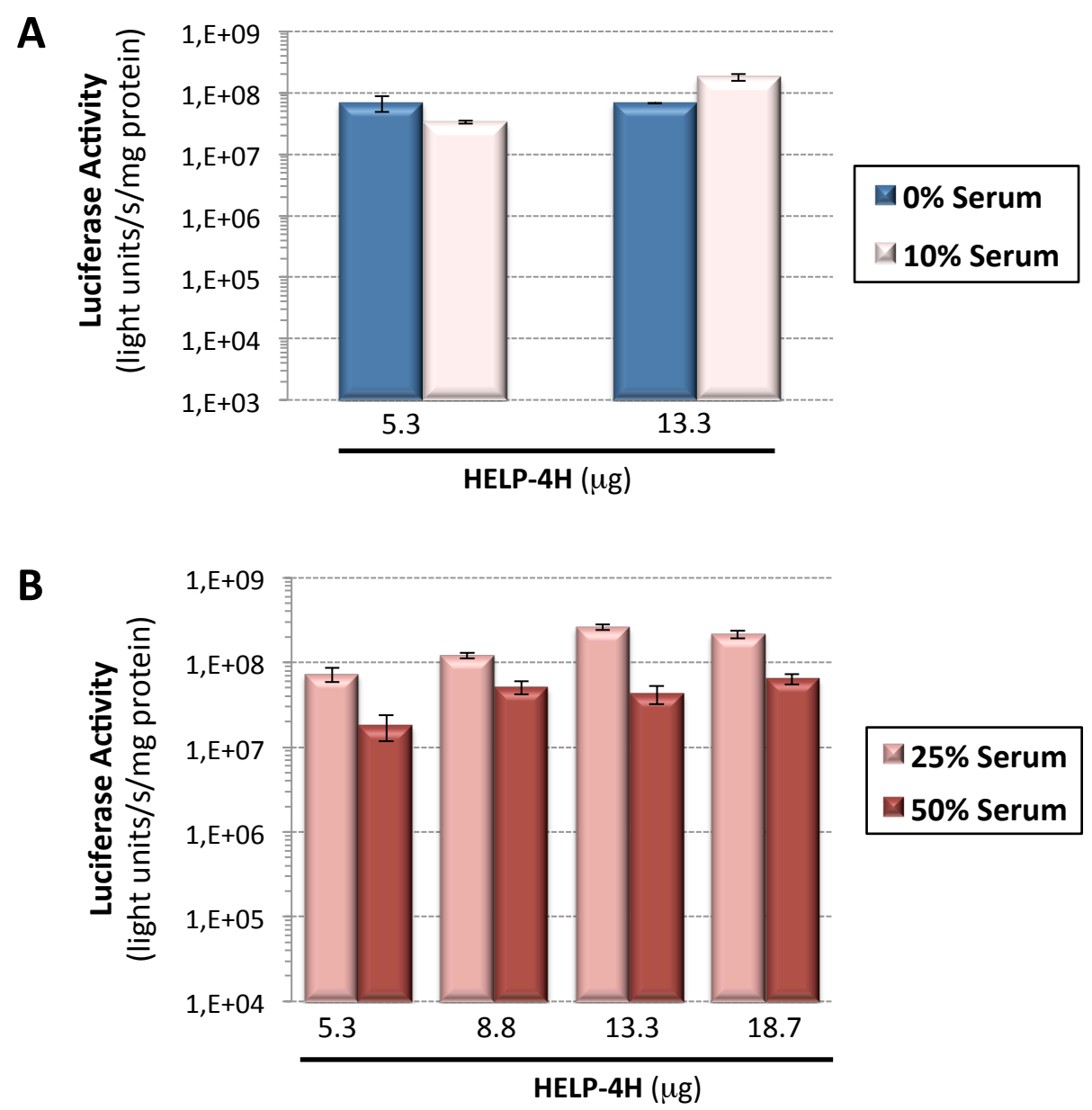

Figure 2. Evaluation of the transfection activity on MRC5-V2 in the presence of serum. Transfection was performed in 48 well-plates using $0.75 \mu \mathrm{g} /$ well of the plasmid encoding for luciferase. Increasing amounts of peptide were mixed in $150 \mathrm{mM} \mathrm{NaCl}$ with a constant amount of plasmid. The indicated amounts of peptide in $\mu \mathrm{g}$ are given for $1 \mu \mathrm{g}$ of DNA. The complexes were incubated with cells for 2.5 hours in medium containing or not serum. Thereafter, the medium was removed and replaced with 10\% serum-containing DMEM. Luciferase activity was measured $42 \mathrm{~h}(\mathbf{A})$ and $28 \mathrm{~h}(\mathbf{B})$ post-transfection and it is expressed as total light units $/ 1 \mathrm{~s} / \mathrm{mg}$ protein, and the average of the duplicates $(\mathbf{A})$ or triplicates $(\mathbf{B})$ is shown. Error bars represent the standard deviation of the mean. 

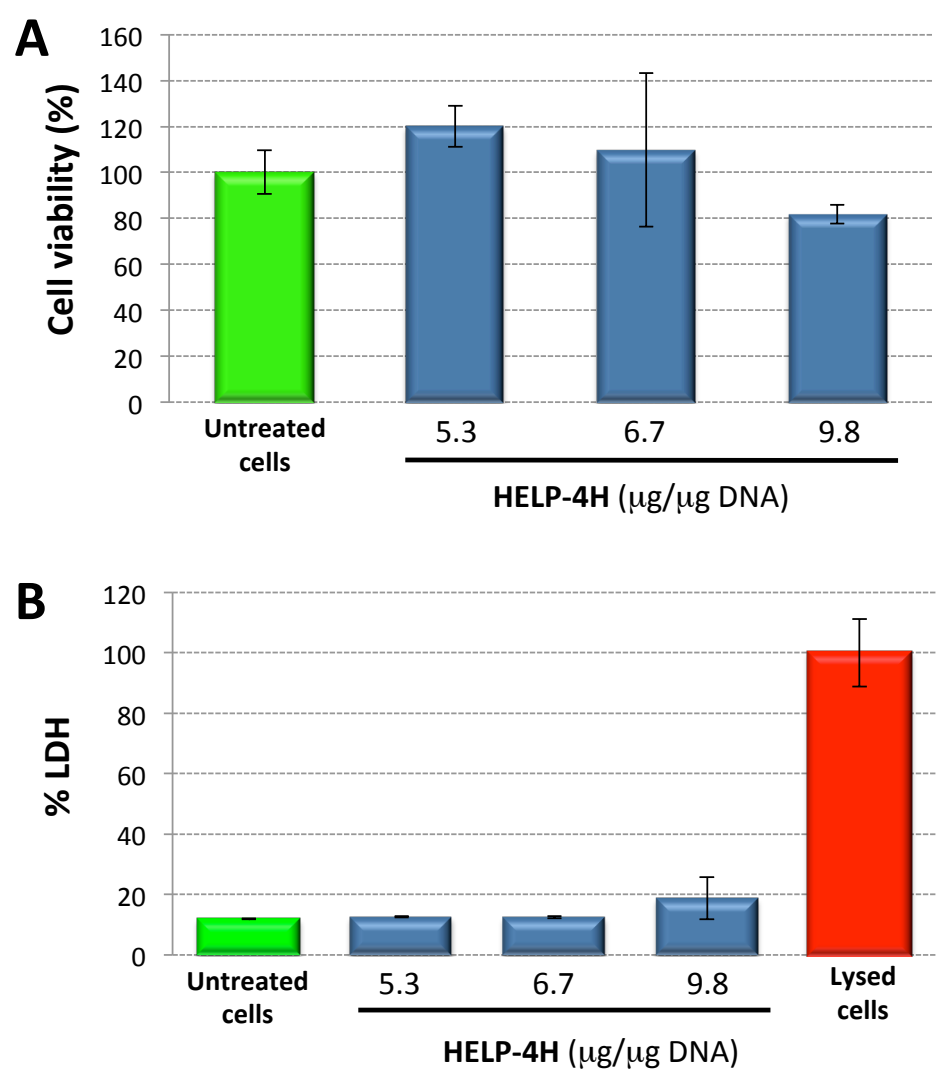

Figure 3. Measurement of the membranolytic and cytotoxic effects of HELP-4H. Increasing amounts of HELP-4H agent were mixed with a constant amount of reporter plasmid ( $3 \mu \mathrm{g}$ per quadruplicate of DNA) and the complexes were incubated for 2.5 hours with MRC5-V2 cells in 48-well plates. Using the same plates, 3 different measurements were made: (A) cell viability MTT assay $(n=3) 24$ h day post-transfection; (B) LDH assay $(n=4)$ after the 2.5 hours period of incubation with the complexes; and lastly luciferase activity $(n=1) 24 h$ post-transfection (not shown). 


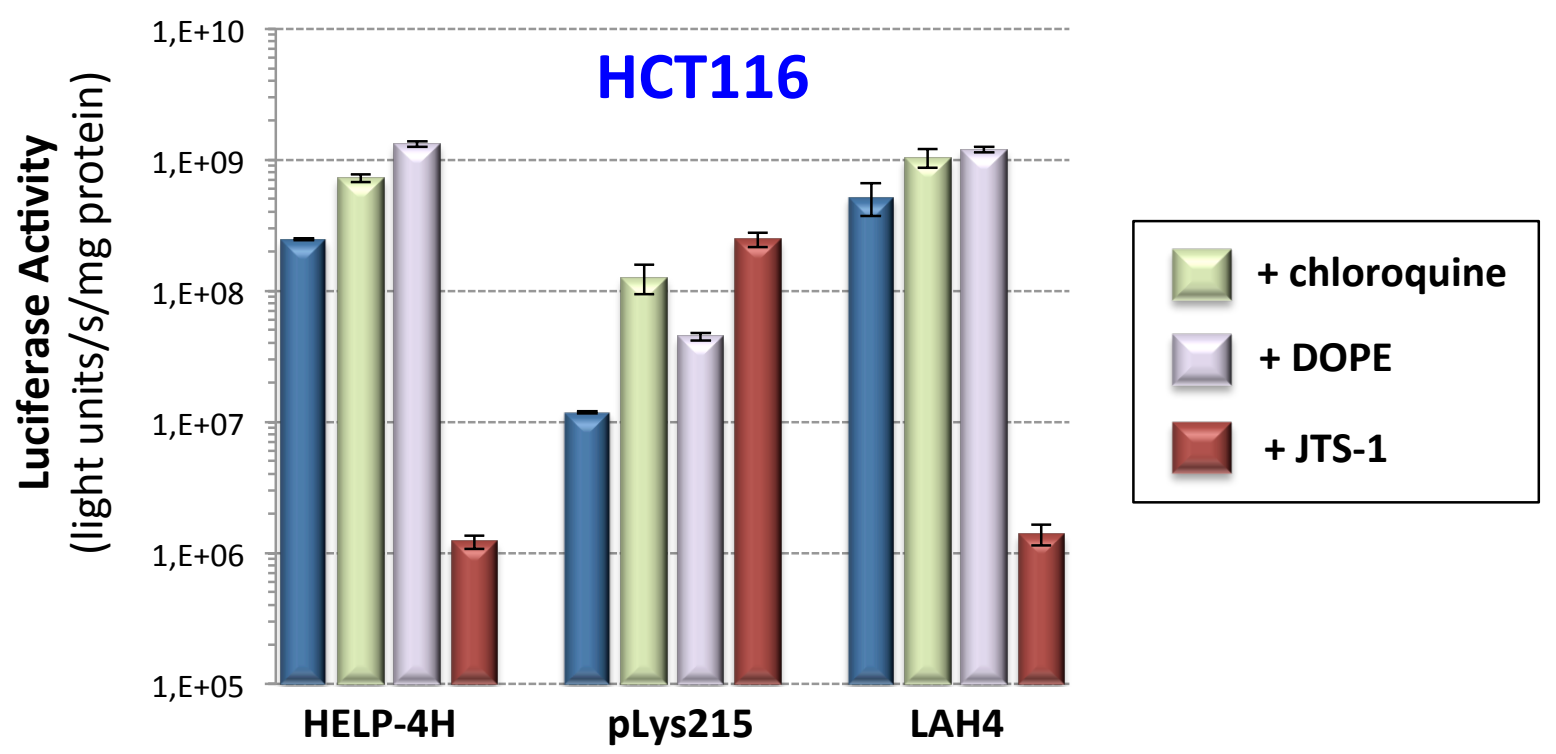

Figure 4. Transfection in the presence of helper agents. Transfection of HCT116 cells was performed in duplicates in 48 well-plates using $0.75 \mu \mathrm{g}$ DNA/well. HELP-4H was used at $2.66 \mu \mathrm{g} / \mu \mathrm{g}$ DNA, LAH4 at a w/w ratio of $8 / 1$ and $\mathrm{pLys} 215$ at $\mathrm{w} / \mathrm{w}=1.66$. The complexes were incubated for 2.5 hours in serum-free medium. Thereafter, the medium was removed and replaced with serum-containing medium. Luciferase activity was measured $24 \mathrm{~h}$ posttransfection and it is expressed as total light units $/ 1 \mathrm{~s} / \mathrm{mg}$ protein, and the average of the duplicates is shown. Error bars represent the standard deviation of the mean. Chloroquine was used at a final concentration of $100 \mu \mathrm{M}$. For generating the ternary complexes, we added respectively $5 \mu \mathrm{g}$ DOPE and $10 \mu \mathrm{g}$ JTS-1 (for a duplicate) to the HELP-4H, pLys 215 and LAH4 complexes. 

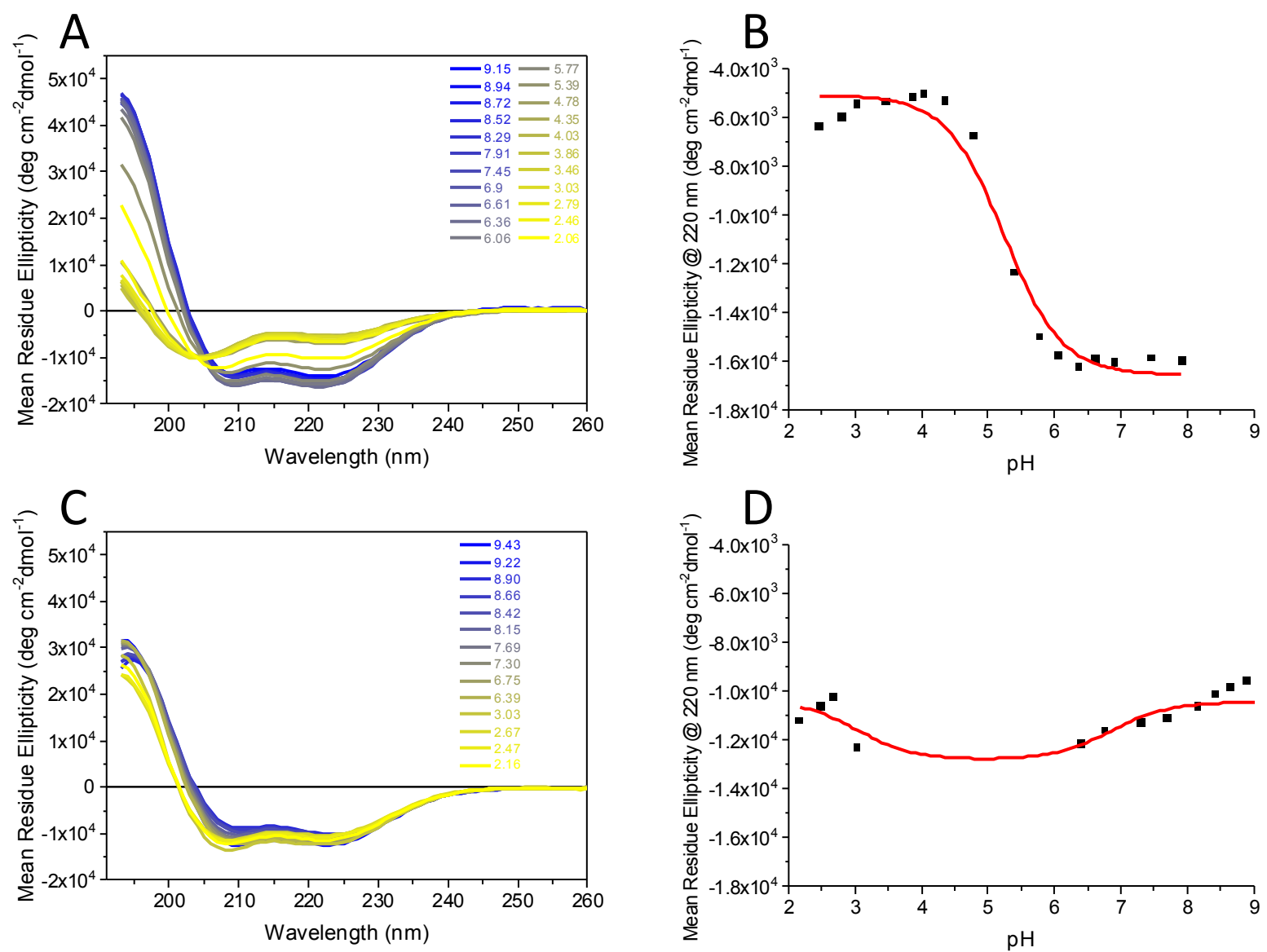

Figure 5. HELP-4H does not undergo a substantial pH-dependent conformational change. Far-UV CD spectra (A/C) and plots of CD @ $220 \mathrm{~nm}(\mathbf{B} / \mathbf{D})$ show that LAH4-L1 $(\mathbf{A} / \mathbf{B})$, unlike HELP-4H (C/D), undergoes a conformational change from $\alpha$-helix to disordered conformation during acidification with a midpoint of $\mathrm{pH} 5.2$. 

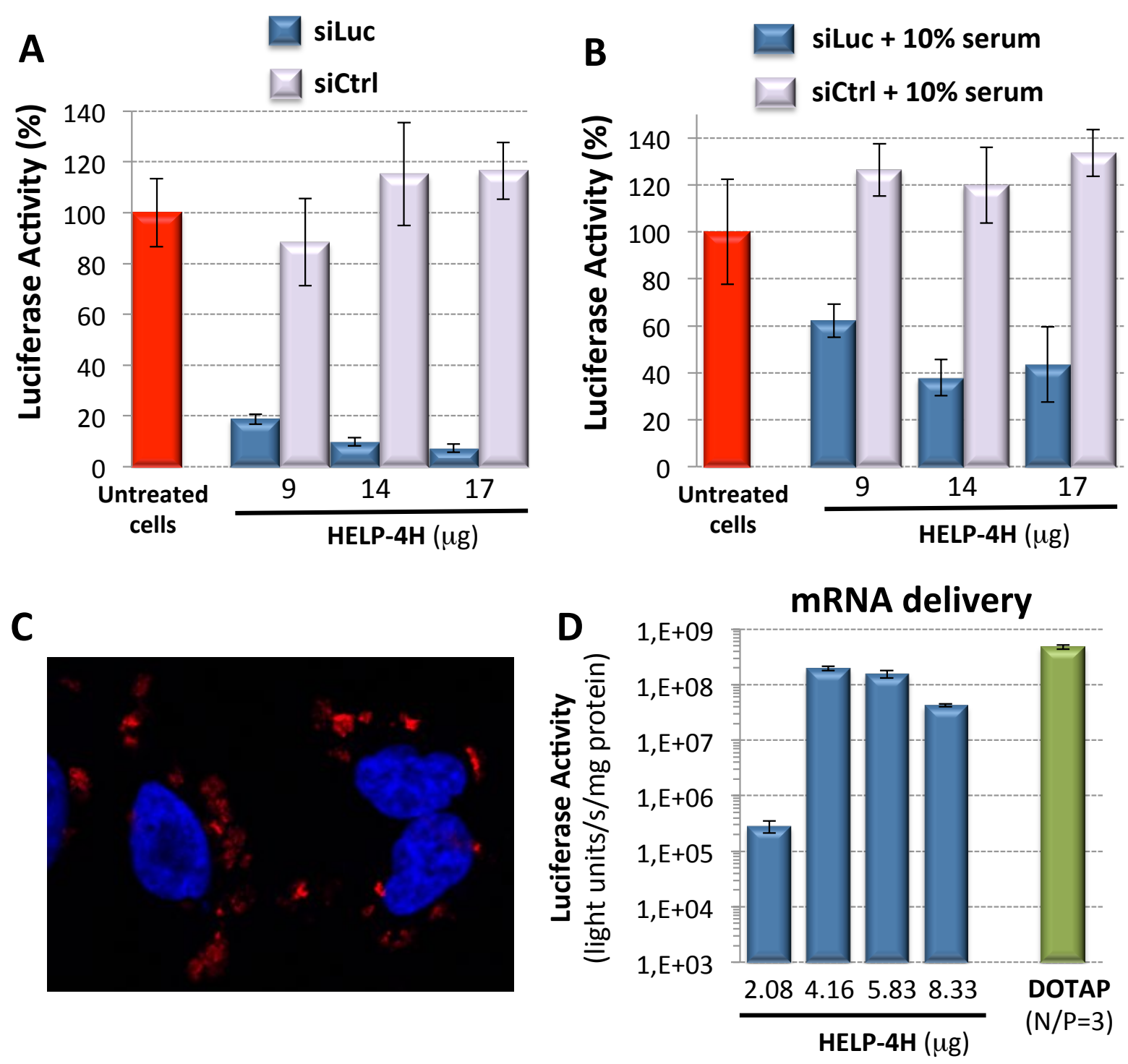

Figure 6. siRNA and mRNA delivery. siRNA transfection of A549-Luc cells was performed in triplicates in 48 well-plates using $0.167 \mu \mathrm{g}$ siRNA/well $(=50 \mathrm{nM})$. We used two siRNAs: one that targets the luciferase mRNA (siLuc; blue bars) and the second which is a control siRNA (siCtrl; purple bars). The indicated amounts of peptide are given for $1 \mu \mathrm{g}$ of siRNA. The complexes were incubated for $3 \mathrm{~h}$ in serum-free (A) or serum-containing (B) DMEM. Thereafter, the medium was removed and replaced with serum-containing medium. Luciferase activity was measured $48 \mathrm{~h}$ post-transfection and was expressed as total light units $/ 1 \mathrm{~s} / \mathrm{mg}$ protein. The siRNA delivery efficiency was then expressed as percent of luciferase remaining after treatment as compared to non-treated cells ( $=100 \%$; red bar). Error bars represent the standard deviation of the mean. (C) Confocal microscopy of A549-Luc cells transfected for $4 \mathrm{~h}$ with HELP-4H/siRNA-Cy5 complexes (17 $\mu \mathrm{g}$ peptide/ $\mu \mathrm{g}$ siRNA; final siRNA concentration $=50 \mathrm{nM}$ ). DAPI (blue stain) was used for nuclear staining. Images were taken using a Leica DMI 4000 microscope with a $\times 63$ objective. (D) mRNA transfection into HCT116 cells. Transfection was performed in duplicates in 96 well-plates using $0.3 \mu \mathrm{g}$ mRNA Luciferase/well. The complexes were incubated for 2.5 hours in serumfree RPMI medium. Thereafter, the medium was removed and replaced with serumcontaining medium. Luciferase activity was measured $24 \mathrm{~h}$ post-transfection. Only the best condition is shown for DOTAP $(\mathrm{N} / \mathrm{P}=3)$. The indicated amounts of HELP-4H peptide are given for $1 \mu \mathrm{g}$ of mRNA. 